\title{
Escrita e Projeto Museológico: uma análise a partir do Museo Nazionale Preistorico Etnografico Luigi Pigorini di Roma
}

\author{
Rafael de Oliveira Rodrigues ${ }^{1}$ \\ Universidade Federal de Alagoas, Maceió, Alagoas, Brasil \\ E-mail: rafaelorodrigues@gmail.com
}




\section{Resumo}

A proposta deste artigo é lançar uma reflexão sobre o projeto museológico do Museo Nazionale Preistorico Etnografico Luigi Pigorini di Roma (Museu Nacional Pré-Histórico Etnográfico Luigi Pigorini de Roma). A análise concentrou-se nas exposições permanentes, uma pré-histórica, outra etnográfica. Tomando como ponto de partida a ideia de que por trás de cada projeto museológico existe um texto escrito, identificou-se que o Museu Luigi Pigorini adota um projeto racionalista, baseado em uma tipologia de escrita museal explicativa, a qual reduz a complexidade de suas coleções ao discurso científico.

Palavras-chave: Museo Nazionale Preistorico Etnografico Luigi Pigorini di Roma. Escrita Museal. Projeto Museológico. Objetos de Coleções.

\section{Abstract}

This paper proposes to launch a discussion on the museological project of the Museo Nazionale Preistorico Etnografico Luigi Pigorini di Roma (Luigi Pigorini National Prehistoric and Ethnographical Museum of Rome). Our analysis focused on two permanent exhibitions, one prehistoric and the other ethnographic. Starting with the idea that there is a written text behind each museological project, we identified that the Luigi Pigori Museum adopts a rationalistic project, based on a museologically explanatory writing typology, which reduces the complexity of its collections to the scientific discourse.

Keywords:Museo Nazionale Preistorico Etnografico Luigi Pigorini di Roma. Museological Writing. Museological Project. Collection Objects. 


\section{Introdução}

Dartindo do princípio de que por trás de cada exposição museográfica existe um projetista, munido de caneta e papel, escrevendo as tramas e os sentidos que serão o alicerce da narrativa museal, procurouse analisar a tipologia de projeto e de escrita adotada pelo Museo Nazionale Preistorico Etnografico Luigi Pigorini di Roma (Museu Nacional Pré-Histórico Etnográfico Luigi Pigorini de Roma).

O Museu nasceu dentro do Colégio Romano, num antigo gabinete de curiosidades ligado à Igreja Católica, no século XVII. Com o fim da soberania política da Igreja, ele teve suas portas fechadas e só voltou a funcionar no século XIX, quando Luigi Pigorini (1842-1925), famoso paleontólogo italiano, assumiu a responsabilidade de gerir a instituição, sob o nome de Museo do Palazzo del Collegio Romano (Museu do Palácio do Colégio Romano).

Pigorini foi um exímio colecionador e durante os anos em que esteve à frente da instituição não mediu esforços para ampliar o leque de objetos de suas coleções. Para auxiliar no seu projeto, ele manteve contato com uma série de viajantes ligados aos ideais do imperialismo tardio italiano do século XIX (funcionários administrativos, missionários, naturalistas, pintores, entre outros), o que rendeu uma grande variedade de objetos arqueológicos, paleontológicos e também etnográficos. Além da ampliação das coleções para o museu, ele também foi o responsável por incutir à instituição um caráter mais científico, transformando-a em lugar de pesquisa e ensino de referência europeu.

Após seu falecimento, em 1925, constatou-se a necessidade de ampliação do espaço, para que suas coleções de objetos tivessem um 
tratamento mais adequado. Entretanto, os anos posteriores à Grande Guerra e anteriores à Segunda Guerra Mundial terminaram retardando a ampliação, por causa dos custos com o restabelecimento urbano e econômico da Itália.

Apenas entre os anos de 1975 e 1977 o Museu do Palácio do Colégio Romano foi transferido para o imponente Palazzo delle Scienze (Palácio das Ciências). O local passou, então, a agregar o acervo das coleções de objetos pré-históricos e etnográficos sistematizados e colecionados por Pigorini, ao longo dos anos em que esteve à frente da instituição, sendo batizado com o nome de Museo Nazionale Preistorico Etnografico Luigi Pigorini di Roma, em homenagem ao notável cientista.

Atualmente, o Museu Pigorini, como é comumente referenciado em Roma, é considerado uma das instituições de pesquisa mais importantes do mundo por manter em suas coleções objetos etnográficos das Américas do Norte e do Sul e também da África e Oceania, além de ser um centro de referência italiana em pré-história.

Para refletir o tipo de projeto e de escrita museal adotado pelo Museu Pigorini, este artigo foi divido em quatro partes, além desta introdução. De início, serão apresentadas as transformações que têm ocorrido na museologia ao longo do século XX. Em seguida, serão tratados dos diferentes tipos de escrita referentes às diferentes tipologias de projetos museais advindos com as transformações na área. Dando continuidade, serão trazidas reflexões sobre o projeto e a tipologia de escrita museal adotada pelo Museu Pigorini para apresentar os objetos de suas coleções. Em seguida, serão apresentadas as considerações finais destacando que, apesar da instituição também ser um museu etnográfico, ela mantém uma tipologia clássica, que tem como base um projeto racionalista, pautado em uma escrita museal que tem como fim último apresentar suas coleções de modo imparcial e explicativo.

É importante dizer que este artigo é fruto de uma etnografia realizada no Museu Luigi Pigorini de Roma, entre os anos de 2013 e 2014, a qual teve como objetivo a elaboração da tese de doutorado intitulada Da crônica de viagem ao objeto museal: notas sobre uma coleção etnográfica brasileira em Roma. 


\section{Velhas Palavras para Novas Práticas}

Já é lugar comum atribuir ao ato de colecionar as bases do que hoje se conhece como um museu. Poulot (2013), na sua história da museologia, por exemplo, chama atenção para o fato de que o colecionismo dos séculos XVII e XVIII fornece as bases ideológicas e tipológicas para inventar pouco a pouco uma ideia de museu na qual a representação a partir de fragmentos da antiguidade será apresentada para ostentação, contemplação e estudo.

Sobre esse período, autores como Chagas (2008) e Padiglione (2008) destacam ainda que era comum a promoção de arquivos e bibliotecas em espaços conhecidos como gabinetes de curiosidades, onde predominavam as coleções de história natural, de antiguidades e de objetos exóticos advindos com a descoberta dos novos continentes.

Saindo da era dos gabinetes de curiosidades, o século XIX assiste à consolidação dos museus como espaços educativos em que o saber científico oferecia as bases de seu funcionamento, promovendo uma maior racionalização de seus métodos de classificação, datação e ordenamento.

Poulot (2013) chama atenção de que, nesse momento de sua história, os museus se abrem como espaços de pesquisa, todavia, ainda muito restritos a um público seleto, pois só uma pequena parcela da população da elite intelectual ou econômica tinha acesso, necessitando de solicitação prévia, ou pagamento pela entrada, para poder consultar seus acervos e bibliotecas e para acessar as coleções.

É apenas no século XX que ocorre uma grande proliferação de museus pelo mundo e, em decorrência disso, povos antes colonizados começam a se apropriar dessas instituições. Nas palavras de Poulot (2013, p. 17):

Ao longo das décadas de 1960 e 1970, o ICOM assumiu o papel de iniciador das novas exigências de utilidade social dos museus e do patrimônio, por meio essencialmente da realização de conferências gerais, mas também por meio da publicação de múltiplos documentos resultantes de seus diferentes comitês. O papel de seus primeiros responsáveis - Georges Henri Rivière, diretor de 1948 a 1966, e Hugues de Varine-Bohan seu sucessor até 1975 - 
revelou-se importante para definir a filosofia da associação. A mesa redonda de Santiago do Chile enfatizou, em particular, a dimensão social dos museus, abrindo uma perspectiva de compromisso por toda parte da profissão que nunca mais foi desmentida.

Essas questões materializadas em documentos das Organizações das Nações Unidas para Educação e Ciência (UNESCO) e do Comitê Internacional de Museus (ICOM) possibilitaram o surgimento de novas perspectivas teórico-metodológicas que lançam as bases para o que autores como Chagas (2008), Kersten e Bonin (2007) chamam de uma nova museologia, pautada por uma nova imaginação museal, em que novas vozes entram em cena para narrar e escrever suas próprias histórias.

Na prática, esses documentos incentivaram uma maior proliferação de museus, a consolidação de uma série de preceitos éticos sobre a aquisição e a representação que se deve fazer dos objetos provenientes de outras culturas que compõem as coleções.

Lançando um olhar reflexivo para essas mudanças, Padiglione (2008) chama atenção para o fato de que, apesar dessas transformações fundamentais, quando se olha para os museus na atualidade, especialmente os de tipologia clássica, percebe-se que a base de trabalho dessas instituições ainda permanece basicamente a mesma: coletar uma série de objetos de fontes e origens distintos, como objetos arqueológicos, paleológicos, ou mesmo etnográficos, catalogá-los e, por fim, construir uma narrativa que atribua sentido e significado a eles.

O processo de montagem desses objetos heterogêneos em uma narrativa expográfica é o que Padiglione define como escrita museal, a qual pode ser sintetizada como o processo pelo qual se produz textualmente as costuras que vão unir objetos de coleções de fontes e origens distintas num projeto museológico que tem como princípio básico apresentá-los numa narrativa bem ordenada.

Nesse sentido, diferentes estilos de escrita museal podem ser utilizadas nos museus e, dependendo do projeto museológico de cada instituição, podem suscitar nos visitantes ou a expectativa de receber informações específicas, advindas de contextos de escrita mais explicativos, que apresentam sua narrativa priorizando o ordenamento 
lógico da exposição; ou convidá-los para pensar novas possibilidades interpretativas sobre os objetos de coleções, por meio de um contexto de escrita mais reflexiva, que possibilite pensar as eventuais contradições e lacunas da produção de determinada narrativa expográfica.

\section{Projeto e Escrita Museal}

Segundo Padiglione (2012), na base da museologia está presente um tipo de experimentação visual que promove a construção de mundos sociais baseados num idioma que segue uma lógica de ostentação dos objetos e das coleções. O autor ainda chama a atenção para o fato de que isso seria como um tipo de código que teria como proposta superar a fala e a escrita, uma linguagem que se imagina universal, porque recorre a referentes concretos: os objetos de coleções. Esse código (característico do fazer ciência moderno) pressupõe que o objeto museal em si, seja ele de arte, histórico ou etnográfico,

[...] Uma vez dissociado dos discursos, encontraria autenticidade, valor intrínseco; que a comunicação, uma vez não contaminada com a linguagem e marcos textuais fatalmente históricos e culturais, ganharia em pureza e força expressiva. (Padiglione, 2012, p. 34)

Essa imagem utópica da imparcialidade - em que os objetos falam por si - é demasiadamente ingênua e redutiva. Primeiro, porque essa ideia de autenticidade termina não se sustentando, uma vez que essas peças e objetos foram removidos de seus contextos iniciais e, como foram deslocadas de seus contextos originais para fazer parte das coleções dentro de uma lógica museológica de mercado, torna-se impossível e contraditório evocar qualquer elemento de autenticidade. Segundo, pela simples razão de que, por mais que os objetos de coleções muitas vezes não contem com um texto escrito indicando as principais referências de seus modos de uso e origens, não quer dizer que o modo como os objetos foram expostos e selecionados não estão fundamentados em um tipo de inscrição, precisamente em um tipo de texto escrito.

Essa inscrição, ou este texto, que para um observador desatento se torna invisível, está ali, presente na forma como os objetos são expostos, 
costurando as tramas entre eles, o pesquisador e as diferentes culturas representadas, materializando os arranjos adotados na exposição.

Ao evocar esse texto escrito que subjaz à organização dos objetos numa exposição de museu, Padiglione (2012) sugere uma interessante chave interpretativa para analisar as dinâmicas museais e seus contextos histórico-culturais. Mas a ideia não é de todo nova.

Em A Invenção do Cotidiano, por exemplo, Certeau já reconhece o poder da escrita em homogeneizar e reorganizar, em nível simbólico, ambientes e contextos de origens diversas:

Diante da página em branco, cada criança se coloca na posição do industrial, do urbanista ou do filósofo cartesiano [...] E se predispõe a gerir o espaço, autônomo e distinto, onde coloca em prática uma vontade própria. O modelo de uma razão produtiva se inscreve em um não lugar: $\mathrm{o}$ papel [...] Representa o projeto da escrita em nível de uma sociedade inteira que tem ambição de se construir como página em branco em relação ao passado, de se escrever, ou seja, de produzir-se como sistema próprio, e de refazer a história segundo um modelo fabricado por ela própria. (Certeau, 2001, p. 198, tradução nossa)

Padiglione (2012) complementa a argumentação de Certeau destacando que a modernidade vem para prefigurar a sociedade como um texto, um projeto que se constitui como uma vontade de se distinguir do discurso recebido da oralidade, do mundo mítico, da tradição. Se no cosmo tradicional o sujeito seguia possuído pelas vozes do mundo, agora, diante de um espaço próprio, a página em branco, ele vê organizado e materializado o seu fazer.

Tomando como ponto de partida o argumento de Padiglione (2012), é possível refletir que a modernidade traz como princípio as ideias de ciência e de projeto, sendo o projetista o ser humano racional, dotado de ferramentas e meios intelectuais que o possibilitam projetar e planejar.

Cabe destacar que Certeau parte de uma observação das dinâmicas cotidianas para refletir o lugar do projetista urbano que produz ambientes, muitas vezes, colocando contextos históricos, econômicos, políticos e culturais heterogêneos em uma mesma paisagem homogênea, projetando formas de fazer e de agir em determinados espaços. 
A partir do diálogo entre Certeau (2001) e Padiglione (2012), é possível observar que essa ideia de texto escrito como um projeto, marco da nossa modernidade, também tem servido como base para a museologia moderna, a qual tem adotado a mesma lógica de planejamento do projetista.

Todavia, Padiglione sustenta que, diante da grande proliferação dos museus ao longo do século XX, também tem havido uma grande diversificação de formas de apresentar as coleções de objetos. Essas formas variam de acordo com o projetista e com o estilo de escrita adotado para cada tipologia de museu.

Nesse sentido, o autor apresenta dois estilos de escrita museal: a racionalista/explicativa e a reflexiva/interpretativa. No que se refere ao primeiro estilo, ele destaca que:

No centro da cena museal, é necessário colocar o resultado da investigação pura, que o museu, partenair da Universidade, desenvolve; ou seja, uma explicação das supostas causas, como reconstrução de determinada ordem nada evidente de relações significativas em que os objetos estavam inseridos quando eram utilizados. Dentro da museologia racionalista, o painel com inscrições de textos, esquemas gráficos (mas também desenhos técnicos, fotos e genealogias) vem a desenvolver um papel heroico, pois ele é encarregado de dotar de autoridade científica e cultural uma montagem do contraditório, precisamente enquanto configuração visual [...] fatalmente redutivo à claridade e densidade analítica. (Padiglione, 2012, p. 38)

Seguindo essa linha argumentativa, observa-se que, nos museus de tipologia clássica, há uma tendência à adoção de um estilo de escrita racionalista e explicativa, em que uma série de objetos de fontes e origens distintas, como documentos, fotografias, objetos etnográficos do cotidiano, ou até mesmo obras de arte, são utilizados na confecção de um amálgama muito bem concatenado, causando uma ideia de que os objetos falam por si.

Esse estilo de escrita museal termina, portanto, por causar no visitante uma impressão de imparcialidade por trás da montagem dos objetos de coleções, ou seja, de que há uma verdade última por trás 
de cada narrativa museal, baseada num saber científico. Além disso, termina por anular o projetista por trás das narrativas expográficas.

Baseado na ideia de imparcialidade, esta tipologia de museu adota uma estilo de escritura racionalista, que tem como finalidade última explicar ao visitante a verdade por trás dos objetos das coleções apresentados no percurso expográfico.

É precisamente essa ideia de imparcialidade por trás dos arranjos expográficos que tem sido criticada pela nova museologia, especialmente por Padiglione (2008) no seu projeto de museologia reflexiva.

Partindo do princípio de que existem diversos estilos de escritas museais, os quais variam de acordo com as tipologias e os projetistas de cada museu, Padiglione sustenta a importância dos museus de tipologia clássica em adotar um estilo de escrita etnográfico, renovando sua escrita, para promover narrativas que não sejam meramente explicativas, mas sim reflexivas/interpretativas. Nas palavras do próprio autor, esse estilo de escrita se constitui como:

[...] Parte fundamental da mostra, forma uma composição paisagística, o centro profundo, precário e mutante de um cenário, o puctum móvel de uma instalação [...] Pode-se perceber o conjunto e, ao mesmo tempo, se deter em um detalhe. O efeito que se busca é de que diversas escrituras estimulem a curiosidade, convidem a se aproximar e a consultar. (Padiglione, 2012, p. 44)

Em outras palavras:

Uma paisagem de escritas que remetem ao palimpsesto enquanto multiplicidade de seu interior e, sobretudo, precário, volúvel, sensível às reações das pessoas. Em muitos pequenos museus etnográficos, o visitante percebe a sensação de incompletude que o estimula a contribuir na montagem com informação própria. (Padiglione, 2012, p. 46)

O princípio fundamental da escrita etnográfica está em trazer para o primeiro plano da pesquisa as diferentes vozes que auxiliaram na concepção e no desenvolvimento do trabalho do antropólogo em campo (Clifford, 1986). Em outras palavras, trata-se de apresentar uma 
visão processual do trabalho de coleta de dados, análise e apresentação dos resultados, levando em conta precisamente a participação dos interlocutores da pesquisa.

É precisamente nessa dimensão processual, que são consideradas as vozes dos interlocutores da pesquisa na composição da narrativa etnográfica, na qual Padiglione vai buscar inspiração para defender que as transformações vivenciadas no decorrer do processo de coleta e apresentação dos objetos de coleções devem ser evocadas para compor um estilo de escrita semelhante aos dos antigos palimpsestos, em que diversas inscrições eram realizadas por pessoas de diferentes temporalidades, uma sobreposta às outras, de modo que uma inscrição não anulava a anterior.

Em síntese, o autor sustenta a necessidade dos museus em trazer para suas exposições essa dimensão processual da coleta e da posterior montagem das suas coleções, incentivando uma maior participação, tanto dos grupos representados pelos objetos, quanto dos visitantes, para juntos escreverem e reescreverem as narrativas museais.

\section{O Projetista do Museo Nazionale Preistorico Etnografico Luigi Pigorini di Roma}

Ao voltar o foco das nossas atenções para os museus históricos e etnográficos, particularmente o Luigi Pigorini de Roma, observase que a escrita ocupa um papel central na informação de seus visitantes. Ela suscita neles a convicção de que estão recebendo uma informação racional e especializada, por meio de painéis explicativos, contendo gráficos, anotações e datações; também por meio dos objetos etnográficos; além de catálogos e outros tipos de material escrito sobre diversos contextos culturais.

O Museu Luigi Pigorini nasce no Gabinete de Curiosidades do Padre Athanasius Kircher, no antigo Colégio Romano, no ano de 1600, fundado pela Companhia de Jesus (Nobili, 1990). Com a decadência do poder de decisão da Igreja, o museu foi fechado e assim permaneceu até o ano de 1875, quando Luigi Pigorini, professor de paleontologia italiano da época assumiu a instituição. 
Pigorini estava completamente inserido nas questões políticas de seu tempo, momento histórico em que a Itália se unifica, ficando assim independente do império Austro-Húngaro e Francês. Como político Pigorini veio de uma família politicamente influente de Parma e, ao longo de sua vida, ocupou diversos cargos de gestão e, também, de conselheiro nos assuntos referentes aos bens culturais italianos -, ele esteve empenhado em difundir os ideais de independência em todas as instâncias do seu país e dos outros países europeus. Como cientista, contribuiu para consolidação da ideia de que os etruscos foram a célula matriz de uma identidade italiana e que esse tronco identitário teria dado origem à população que ocupava a península itálica. O Museu Pigorini nasceu, assim, de um projeto político-pedagógico mais amplo: a autonomia italiana de finais do século XIX.

Conseguida essa autonomia, Pigorini concentra suas forças na expansão imperialista da Itália, mantendo contato com diversos personagens do imperialismo do século XIX: colecionadores, administradores, missionários. Esteve alinhado aos ideais evolucionistas, cujo principal objetivo era, num primeiro momento, explicar a evolução da identidade italiana desde a Pré-História, passando pela Roma Clássica, até a contemporaneidade e, num segundo momento, esteve empenhado em explicar a evolução das culturas ao longo da civilização moderna. O Museo Nazionale Preistorico Etnografico Luigi Pigorini di Roma é, portanto, um clássico museu europeu moderno, que, ao mesmo tempo, se apresenta como histórico e etnográfico.

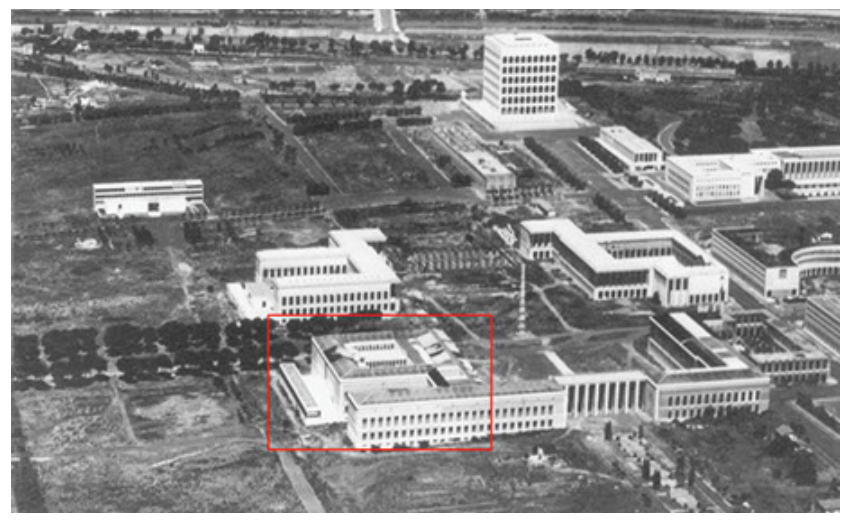

Figura 1: Museo Nazionale Preistorico Etnografico Luigi Pigorini, destaque em vermelho

Fonte: Museo Nazionale Preistorico Etnografico Luigi Pigorini di Roma (2018) 
Nobili (1990) destaca que, após a morte de seu fundador, em 1925, precisamente entre os anos de 1975 e 1977, o museu foi transferido do Palácio do Colégio Romano para o Palazzo delle Scienze (o Palácio das Ciências), no bairro de EUR-Fermi. Nesse momento, além de abrigar as funções de museu, passou a abrigar o Ministério do Patrimônio Cultural e Ambiental italiano. A partir dessa fusão entre o Museu e o Ministério, seu objetivo passou a ser divulgar a política de patrimônio nacional por meio de práticas educativas.

Como é possível observar na Figura 1, o prédio ocupa um quarteirão inteiro. Em destaque em vermelho é possível ver o bloco reservado ao Museu Luigi Pigorini e os outros blocos referentes à administração das outras instituições que ele abriga.

No hall de entrada uma sensação de estupor: o museu é verdadeiro palácio, produzido para dar a impressão de que o visitante está realmente entrando num templo da ciência, como é possível observar na Figura 2.

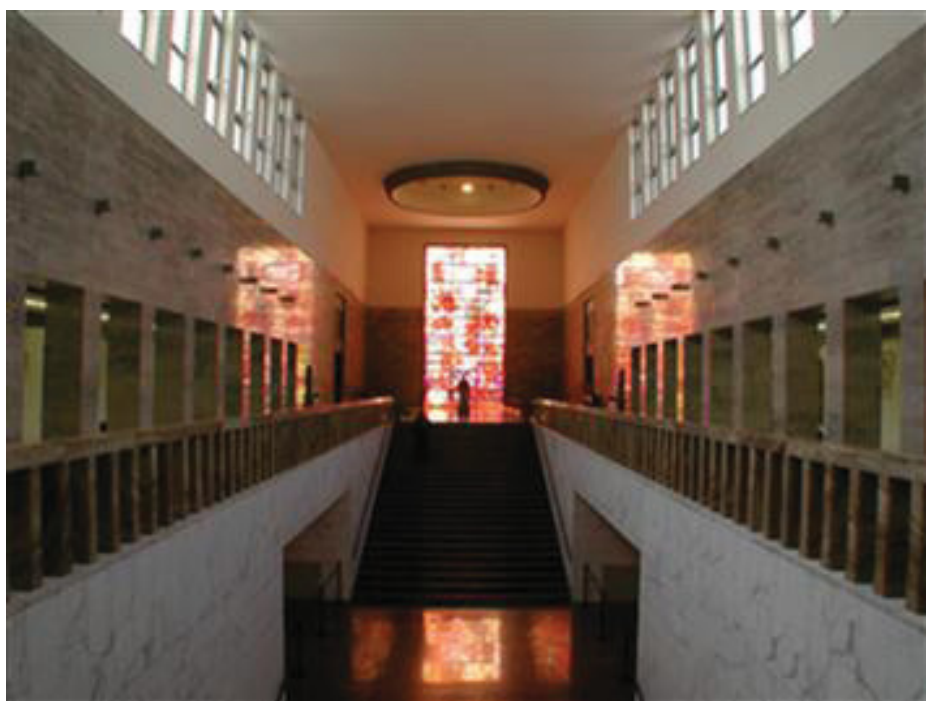

Figura 2: Hall de entrada do Museu

Fonte: Museo Nazionale Preistorico Etnografico Luigi Pigorini di Roma (2018)

Ao adentrar no espaço onde se encontram as exposições permanentes, pré-histórica e etnográfica, é possível perceber que seu projeto parte de uma lógica racionalista, e cada espaço encontrase dividido em temáticas, que vão desde o surgimento da primeira bactéria na terra até o desenvolvimento da vida humana, passando 
por suas diferentes transformações socioculturais ao longo da história. Entrando nos salões reservados às exposições permanentes, o visitante fica imediatamente em contato com um painel explicativo.

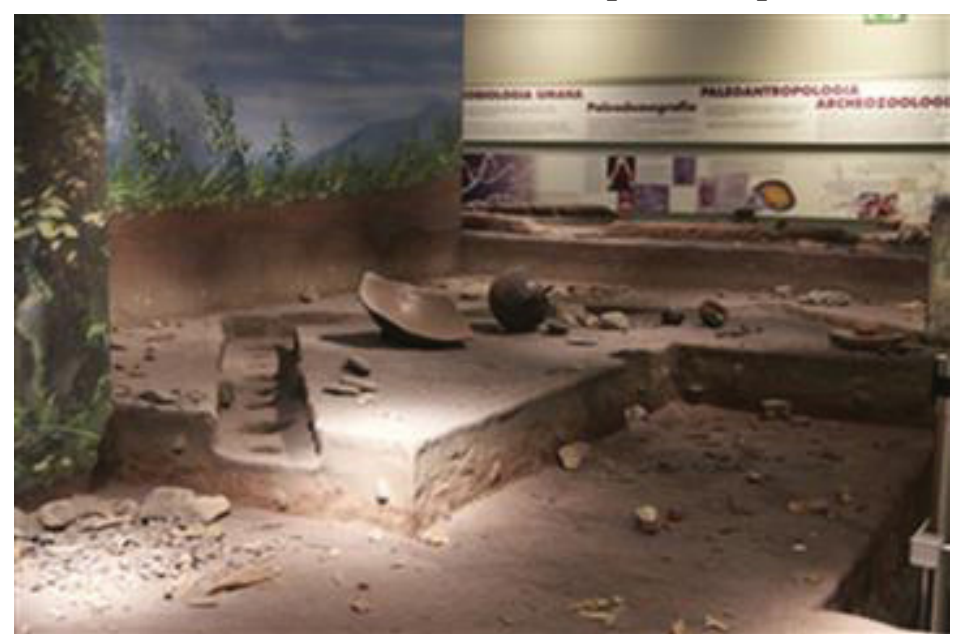

Figura 3: Painel explicativo da evolução humana

Fonte: Museo Nazionale Preistorico Etnografico Luigi Pigorini di Roma

No painel da Figura 3 é apresentada uma síntese da origem da vida na Terra, desde a origem da primeira bactéria no planeta, passando pelos grandes mamíferos, sua posterior extinção, até chegar ao surgimento dos primeiros primatas e, posteriormente, dos seres humanos.

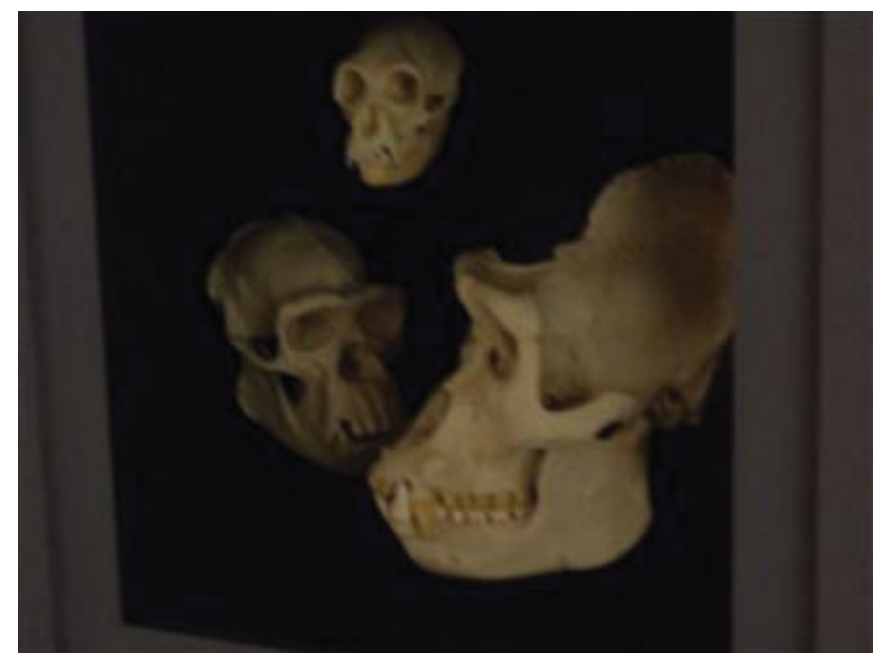

Figura 4: Evolução humana Fonte: Acervo do autor deste artigo 
Deixando-nos guiar pelo percurso sugerido pelo projetista da instituição, chega-se até a parte reservada aos primeiros seres humanos, Figura 4. Percebe-se que ela está fundamentada em denso material textual, no qual as informações causavam a sensação de que os objetos expostos parecem seguir a lógica de um texto, no mesmo sentido que tem um livro de história, por exemplo. Toda essa parte estava baseada em um meticuloso processo de documentação, materializado numa perspectiva racionalista de museu, que se pretende impessoal.

Saindo da parte pré-histórica e adentrando no espaço reservado às coleções etnográficas, o museu segue a mesma lógica. As coleções etnográficas são quatro ao todo: a coleção das Américas, do Sul e do Norte; da África e da Oceania. Em termos expográficos, elas também fazem parte das mostras permanentes e seguem a linha de uma história evolutiva, estando conectadas com as coleções pré-históricas. Tem-se a impressão de que os objetos de coleções com temporalidades e tipologias distintas são organizados com o intuito de produzir a sensação de verdade científica acerca da evolução humana.

Na entrada de cada salão, o visitante se vê diante de um texto explicativo, uma síntese histórica, em que é apresentado um pouco de cada cultura da qual os objetos faziam parte antes de chegarem ao museu. Acompanhada dessa síntese, há ainda uma breve descrição das peças: de onde vieram, como eram utilizadas, para que serviam em seus contextos originais.

Chegando ao salão reservado à Coleção da América do Sul, percebese que, além dos objetos referentes aos diferentes povos indígenas do Brasil, a coleção também conta com objetos de povos das antigas culturas andinas, maias e astecas. 


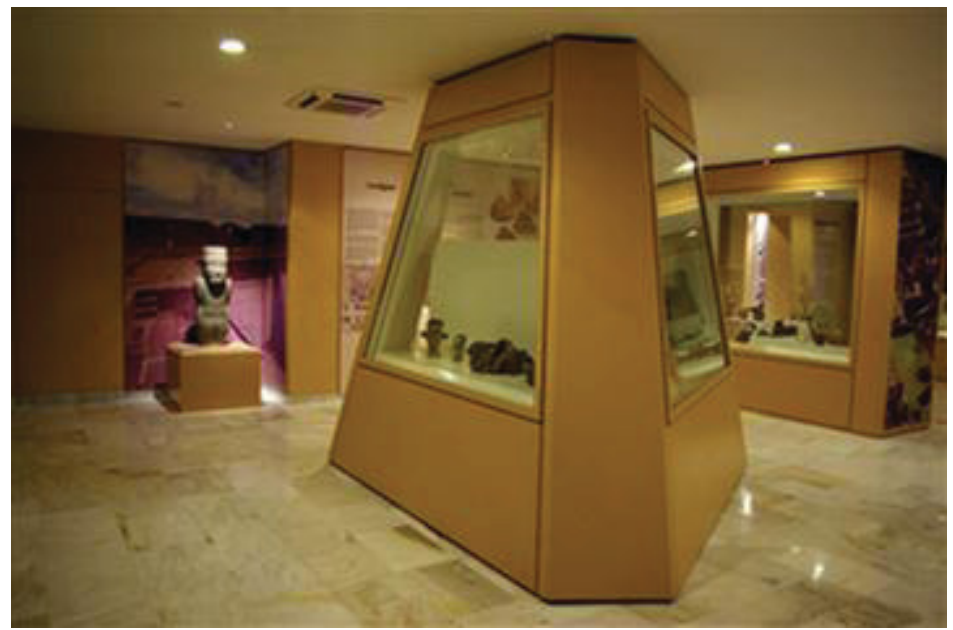

Figura 5: Seção América do Sul

Fonte: Museo Nazionale Preistorico Etnografico Luigi Pigorini di Roma (2018)

Na Figura 5, é possível observar que, de modo semelhante à parte reservada à pré-história, a escrita museal das seções também segue uma cronologia histórica evolutiva, em que os objetos são posicionados de modo a ilustrar a evolução histórica das antigas civilizações americanas até os Índios do Brasil contemporâneo.

Finalizado o percurso indicado a seguir, do modo como ele havia sido organizado pelo projetista, é possível se deparar novamente com o hall de entrada, sinalizando que, de fato, havíamos chegado ao fim do percurso museal. Resolvemos, então, não sair do museu de imediato, e refazer o percurso no sentido inverso, para ver quais impressões teríamos na volta. Chegando ao fim, que na verdade era o ponto de partida, nos vimos diante de um painel pelo qual havíamos passado sem perceber. Era o painel que contava a história do Museu, a partir do momento em que Luigi Pigorini fora nomeado como gestor.

De repente, eis que nos encontramos diante da imagem de Luigi Pigorini, um senhor já com a idade avançada, com uma longa e imponente barba branca, em trajes típicos de uma figura imponente de finais do século XIX. Em algum lugar, nesse mesmo painel, uma inscrição do próprio Pigorini, em que se lia:

O museu é dividido em duas grandes classes. Uma préhistórica e outra etnográfica. A primeira composta de 
material lítico, mas também de material próximo da primeira idade do ferro. A segunda compreende aquilo que é fabricado e utilizado por famílias que vivem em condições de civilização inferiores à nossa, presas num estágio de selvageria, e a razão do paralelo entre as duas classes reside no fato de que, na infinita variedade de usos e os costumes dos povos menos civilizados que nós, é encontrado ainda hoje a imagem de nosso passado distante, que permite explicar os processos industriais das populações pré-históricas. (L. Pigorini, Bullettino di Paletnologia Italiana, 1881, tradução nossa)

Não foi possível localizar a página na inscrição do painel, apenas que o relato foi publicado no ano de 1881, no anuário de paleontologia, conhecido na Itália como o Bullettino di Paletnologia Italiana (Boletim de Paleontologia Italiana). Apesar disso, o relato é muito ilustrativo da missão do Museu Luigi Pigorini e da ideologia que guiava os principais cientistas desse período histórico.

Nesse sentido, a missão do museu, segundo as palavras de seu próprio idealizador, é justamente explicar. Precisamente, uma explicação que vai para o sentido de instruir o visitante de que as populações de diferentes culturas são um elo perdido entre as populações pré-históricas e o homem civilizado europeu da época. Não é fortuito que o Museo Nazionale Preistorico Etnografico Luigi Pigorini di Roma defina-se, portanto, como lugar de aprendizagem.

Não se pretende com isso utilizar elementos de denúncia de imprensa marrom, para sugerir que o Museu Luigi Pigorini adota ou promove algum tipo de política colonialista na sua agenda. Deve-se lembrar de que Pigorini deu essa declaração em finais do século XIX, momento em que toda visão de mundo de uma época se via balançada com as descobertas do darwinismo, portanto, foram inúmeras as tentativas de aplicar o conceito de evolução para explicar a vida humana em sociedade.

Hoje, assim como todos os museus do mundo, o Museu Pigorini reconhece sua dívida histórica com os povos antes colonizados e problematiza, em grande medida, o modo como os objetos de suas coleções foram adquiridos, muitas vezes, chamando a atenção para a falta de ética dos viajantes que recolhiam esses objetos. O Museu 
Pigorini se atualizou, assim, ao discurso da nova museologia. Entretanto, muito da sua prática ainda está vinculada ao paradigma clássico da museologia.

Este museu inscreve-se, portanto, no que Padiglione (2012) tem chamado de uma museologia racionalista, a qual tem deslocado o foco do interesse da coleção para o discurso científico.

O museu se propõe a explicar a realidade como construção de relações significativas, as quais não são colocadas em evidência para o espectador. Em outras palavras, no Museo Nazionale Preistorico Etnografico Luigi Pigorini di Roma - adepto de um tipo de museologia racionalista - o painel com inscrições de textos e, também, desenhos técnicos, fotos e genealogias, torna-se encarregado de dotar de autoridade científica e cultural uma montagem do contraditório.

Torna-se, desse modo, redutivo com respeito à claridade e densidade analítica do interlocutor, e até mesmo no potencial interpretativo que oferece para seu público. Confirma ao visitante aquele procedimento científico do projetista que propõe como meta a separação do empírico e do interpretativo, do analítico e do figurativo (Padiglione, 2012). Toda a ambiguidade e momentos de imprecisão são deturpados com base numa escrita mais explicativa do que reflexiva.

O que termina produzindo uma narrativa com teor de verdade absoluta, que promove um saber monológico e desencarnado, com uma linguagem impessoal e institucional. Muitas vezes, com o intuito de promover uma maior transparência, termina correndo o risco de infantilizar o público sem sequer alimentar a capacidade de se maravilhar ou de refletir para além do caráter explicativo adotado pelo projetista do museu.

A escrita museal adotada pelo projetista do Museu Luigi Pigorini termina por colocar no espaço das coleções apenas fatos que se consideram importantes dentro de determinadas conjunturas políticas.

A escrita é utilizada, portanto, como modo de releitura do passado, o qual reescreve a história e, sobretudo, descontextualiza e ressignifica objetos, como se o espaço museal fosse um espaço em branco de uma folha de papel, na qual, por meio de um projeto racionalista/explicativo, imprime-se uma escrita harmônica. 


\section{Considerações Finais}

O presente artigo teve como objetivo refletir dos diferentes tipos de escrita museal e de projetos museológicos, tomando como referente empírico o Museo Nazionale Preistorico Etnografico Luigi Pigorini di Roma.

Num primeiro momento, observa-se que a museologia tem passado por diversas transformações, especialmente na segunda metade do século XX. Mudanças que contribuíram para uma nova configuração ética e metodológica, no que tange à coleta e à representação da diversidade cultural, por meio dos objetos de suas coleções e, também, no modo como outras populações, antes desprovidas de legitimidade para se representar, começaram a se apropriar dos museus como instrumento de autoafirmação social. Essas transformações foram imprescindíveis para sedimentar os museus como espaços de ação e de transformação social e política.

Por meio de instituições como a UNESCO e o ICOM, essas novas bases éticas e metodológicas se materializaram e passaram a guiar as agendas dos museus já consolidados, além de contribuir para estimular o surgimento de novos espaços voltados para representação de pequenos grupos.

Num segundo momento, percebe-se que essas transformações influenciaram sobremaneira no surgimento de novos projetos museológicos. Fazendo analogias entre o esquema museal e o projeto moderno, observa-se que a modernidade impõe um modelo de sistematização do conhecimento que prima pela organização, tabulação e classificação. Além de tudo, inaugura um saber factível, ou seja, legitimado pelo ver (experimento), sendo a escrita (empiria) um processo fundamental de validação dos projetos museológicos.

Tomando como base autores como Certeau (2001) e Padiglione (2012), foi possível refletir sobre duas tipologias de escrita museal, relacionadas a dois projetos museológicos específicos. Primeiro a escrita explicativa, base para o projeto racionalista de museu, a qual parte do princípio de que os objetos falam por si, para explicar de modo imparcial ao visitante a verdade por trás das coleções. Baseada numa ideia de autenticidade dos objetos, ela produz uma narrativa que encadeia 
argumentos lógicos de forma bem concatenada. Termina por colocar seu foco explicativo mais no discurso científico do que nas tramas que envolvem a aquisição dos objetos, ou mesmo a representação das culturas por meio destes.

Dando continuidade, lançou-se uma reflexão sobre o segundo tipo de escrita museal, a reflexiva, presente no projeto de museu interpretativo. Baseada no modelo de escrita etnográfica, em que os processos de coleta e montagem dos dados são apresentados, observa-se que ela está mais empenhada em promover no visitante a vontade de conhecer mais sobre os contextos dos objetos. O foco sai do discurso científico e se volta para o objeto das coleções (seus deslocamentos, o processo de montagem da exposição), incentivando o visitante a refletir outras possibilidades ou mesmo a contribuir com a narrativa museal.

Em seguida, analisou-se o projeto museológico e a escrita museal adotada pelo Museu Luigi Pigorini de Roma, observando que apesar de ser um museu pré-histórico e etnográfico, ele é uma tipologia clássica de museu. Adepto de um projeto racionalista, ele utiliza uma escrita explicativa, cujo fim último é descontextualizar e ressignificar os objetos de suas coleções com base no discurso da imparcialidade científica.

Ao refletir sobre o modo de operar dos museus com base nos pressupostos de Certeau (2001) e de Padiglione (2012), percebeu-se a centralidade da prática museal de reler o passado, reescrever a história e, sobretudo, de descontextualizar e ressignificar objetos, de desenhar ambientes e redefinir lugares, como se fossem páginas em branco sobre as quais se imprimem projetos, vontades e diferentes interesses.

\section{Agradecimentos}

É importante dizer que este artigo é fruto de uma etnografia realizada no Museu Luigi Pigorini de Roma, entre os anos de 2013 e 2014, que teve como objetivo a elaboração da tese de doutorado intitulada Da crônica de viagem ao objeto museal: notas sobre uma coleção etnográfica brasileira em Roma. Cabe ainda destacar que o presente trabalho foi realizado com apoio da Coordenação de Aperfeiçoamento de Pessoal de Nível Superior - Brasil (CAPES) - código de financiamento 001. 


\section{Referências}

CERTEAU, Michel de. L'invenzione del quotidiano. Roma: Edizioni Lavoro, 2001.

CHAGAS, Mário. A radiosa aventura dos museus. In: DODEBEI, Vera; ABREU, Regina (org.). E o patrimônio? Rio de Janeiro: Contracapa, Programa de Pós-Graduação em Memória Social da Universidade Federal do Estado do Rio de Janeiro, 2008. p. 113-123.

CLIFFORD, James. Introduction: partial truths. In: CLIFFORD, James; MARCUS, George. Writing culture: the poetics and politics of ethnography. Berkeley, Los Angeles, London: University of California Press, 1986.

KERSTEN, Márcia S. de A.; BONIN, Anamaria A. Para Pensar os museus, ou 'Quem deve controlar a representação do significado dos outros?'.

MUSAS - Revista Brasileira de Museus e Museologia, Rio de Janeiro: Instituto do Patrimônio Histórico e Artístico Nacional, Departamento de Museus e Centros Culturais, n. 3, p. 117-128, 2007.

MUSEO Nazionale Preistorico Etnografico Luigi Pigorini di Roma. [2018]. Disponìvel em: http://www.pigorini.beniculturali.it/preistoria.html. Acesso em: 19 nov. 2018.

NOBILI, Carlo. Per una storia degli studi di Antropologia Museale - Il Museo "Luigi Pigorini" di Roma. Lares - Rivista Trimestrale di Studi Demo-Etno-Antropologici, Roma, LVI, n. 3, Luglio-Settembre, 1990.

PADIGLIONE, Vincenzo. O lugar onde todas as palavras se concretizam. Cinco presenças da escrita em pequenos museus etnográficos. In: CASTELLS, Alicia Norma de; NARDI, Letícia (org.). Patrimônio Cultural e Cidade Contemporânea. Florianópolis, Editora da UFSC, 2012. 280p. . Lingua biforcuta: una risorsa riflessiva. In: PADIGLIONE, V. Poetiche dal museo etnográfico: Spezi morali e kit di sopravvivenza. Imola (BO), Editrice La mandrágora, 2008.

POULOT, Dominique. Museu e Museologia. Belo Horizonte: Autêntica Editora, 2013.

Recebido em 21/05/2018

Aceito em 19/09/2018

Este texto está publicado sob uma Licença Creative Commons - Atribuição-NãoComercialCompartilhaIgual 4.0 Internacional - CC BY NC AS.

Mais detalhes em: https://creativecommons.org/licenses/by-nc-sa/4.0/deed.pt_BR 